\title{
Social Aspects of Gluten-free Living
}

\author{
Diana Deleanu ${ }^{1,2}$, Nicolae Miron ${ }^{1,2}$, Iulia Lupan ${ }^{3}$, Gabriel Samasca, ${ }^{1,4}$ \\ ${ }^{1}$ Department of Immunology and Allergology; Iuliu Hatieganu University of Medicine and Pharmacy, Cluj-Napoca, Romania \\ ${ }^{2}$ Department of Internal Medicine, Regional Institute of Gastroenterology and Hepatology "Prof. Dr. Octavian Fodor" \\ ${ }^{3}$ Molecular Biology Center, Institute for Interdisciplinary Research on Bio-Nano-Sciences, “Babes-Bolyai” University, \\ Cluj-Napoca, Romania \\ ${ }^{4}$ Emergency Hospital for Children, Cluj-Napoca, Romania \\ *Corresponding author: Gabriel.Samasca@umfcluj.ro
}

Received September 01, 2014; Revised September 08, 2014; Accepted September 21, 2014

Cite This Article: Diana Deleanu, Nicolae Miron, Iulia Lupan, and Gabriel Samasca, "Social Aspects of Gluten-free Living.” International Journal of Celiac Disease, vol. 2, no. 3 (2014): 118-118. doi: 10.12691/ijcd-2-3-9.

\section{Case Report}

DE is a 35-year old patient, diagnosed in 2005 with celiac disease, megaloblastic anemia and psoriasis. Histopathological examination of duodenal biopsy at diagnosis revealed chronic atrophic duodenitis Marsh Type IIIb. An upper endoscopy showed no esophageal lesions, normal stomach-gastric body, normal antrum and D2 bulb with flat mucosa.

The patient had 3-4 stools per day with mucus, nausea, rights upper quadrant pain and loss of appetite, with 7 days ago before hospital admission from this year. On admission is highlighted: size $160 \mathrm{cms}$, weight $40 \mathrm{~kg}$ underweight nutritional status with weight loss in recent weeks, uncharacteristic facies, pale skin and mucous membranes. We retained from anamnesis the following: smoking 4-5 cigarettes per day, coffee 1 per day and related working conditions. The patient presented high school education, with a job in the sports production and a salary of 300 USD. The laboratory examinations showed hemoglobin = $9.6 \mathrm{~g} / \mathrm{dl}$, Red Blood Cell $=3.880 .000 / \mathrm{mm} 3$, hematocrit $=$ $30 \%$, IgA tissue transglutaminase antibodies = positive 60 units (Cut-off = 25 units, ELISA), antiendomisium antibodies $=$ positive (indirect immunofluorescence). Histopathological examination of duodenal biopsy showed chronic duodenal villous atrophy, intraepithelial lymphocytosis (> 30/100 enterocytes) and cryptic hyperplasia aspects compatible with celiac disease Marsh Type IIIc. The diagnosis was: gluten enteropathy, moderate microcytic anemia secondary to dehydration syndrome.

\section{Discussions}

Why gluten-free diet did not to help? Women eat less than men [1]. Social position can have negative consequences on the financial situation and thus on gluten-free products [2]. The women also described more distress caused by the food restrictions [3]. Social issues should be considered in the treatment of patients with celiac disease [4]. Adherence to gluten-free diet is an essential part of quality of life of patients with celiac disease [5]. The families of patients and the society should support these patients [6]. Therefore celiac disease is an interdisciplinary problem [7] that requires a team-based management of patients with celiac disease [8]. After diagnosis, a strict gluten-free diet is necessary [9]. But although some gluten-free products are partially covered by health insurance [10], the financial support for patients with celiac disease does not exist in many states.

\section{References}

[1] Ansaldi N, Dell'Olio D, Tavassoli K, Faussone D, La Vecchia A, Bramante L. Adherence to a diet and theMinerva Med 1992;83(78): 439-43.

[2] Calsbeek H, Rijken M, Bekkers MJ, Kerssens JJ, Dekker J, van Berge Henegouwen GP. Social position of adolescents with chronic digestive disorders. Eur J Gastroenterol Hepatol 2002; 14(5): 543-9.

[3] Hallert C, Sandlund O, Broqvist M. Perceptions of health-related quality of life of men and women living with Scand J Caring Sci 2003; 17(3): 301-7.

[4] Sverker A, Hensing G, Hallert C. 'Controlled by food'- lived experiences of J Hum Nutr Diet 2005; 18(3): 171-80.

[5] Wagner G, Berger G, Sinnreich U, Grylli V, Schober E, Huber WD, Karwautz A. Quality of life in adolescents with treated influence of compliance and age at diagnosis. J Pediatr Gastroenterol Nutr 2008; 47(5): 555-61.

[6] Samașca G, Iancu M, Pop T, Butnariu A, Andreica M, Cristea V, Dejica D. Importance of the educational environment in the evolution of celiac disease. Lab Medicine 2011; 42(8): 497-501.

[7] Makovicky P, Samasca G. Present View of the Management and Tasks in the Celiac Disease Field: From Diagnosis to Therapy. International Journal of Celiac Disease 2013; 1(1): 3-5.

[8] Rajpoot P, Makharia GK. Problems and challenges to adaptation of gluten free diet by Indian patients with celiac disease. Nutrients. 2013; 5(12): 4869-79.

[9] Guandalini S, Assiri A. Celiac disease: a review. JAMA Pediatr. 2014; 168(3): 272-8.

[10] Kabátová J. Epidemiology of Celiac Disease in Slovakia: Life Conditions of Celiac Disease Patients in Slovakia. International Journal of Celiac Disease 2014; 2(2): 38-39. 